\title{
Prevalence and Risk factors leading to Vascular access failure among Hemodialysis Patients (Suggested Nursing Guideline)
}

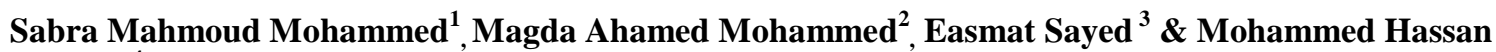 \\ Mostafa ${ }^{4}$. \\ 1. B.SC. Nursing, Faculty of Nursing, Assiut University, Assiut, Egypt. \\ 2. Professor, Adult Nursing Department, Faculty of Nursing, Assiut University, Assiut, Egypt. \\ 3. Lecturer, , Adult Nursing Department, Faculty of Nursing, Assiut University, Assiut, Egypt. \\ 4. Lecturer, Lecturer of Internal Medicine and Nephrology, Faculty of Medicine, Assiut University, Assiut, Egypt.
}

\begin{abstract}
The aim of the study was to identify the prevalence and risk factors of vascular access failure among hemodialysis patients. Patients and method: A descriptive exploratory research design was utilized. This study was conducted in dialysis unit at Assiut University Hospital. The study sample consisted of 200 consecutive adult patients attended to dialysis unit at Assiut University Hospital within a period of 6 months their age ranged from 20 to 65 with mean age (40.76 \pm 13.24$)$ years. Tools: Tool 1: A patients interview questioner sheet. Tools 2: Risk factors and causes of vascular access failure. Results: Incidence of vascular access failure among hemodialysis patients at Assuit University Hospital in over six month was (34.5\%). Their age ranged from 40-65 year. Aging, diabetes, obesity, and infection were the major risk factors for vascular access failure. Conclusion: There was statistical significant relation ship were found between the vascular access failure and duration of dialysis. Recommendation Simple illustrated guidelines about vascular access and risk factors for failure should be available for patients in all dialysis units.
\end{abstract}

Keywords: Hemodialysis, Nursing guideline Prevalence, Risk factors \& Vascular Access Failure.

\section{Introduction}

Hemodialysis is used for patients who are acutely ill and require short-term dialysis for days to weeks until kidney function resumes (Lewis et al., 2014).

Arteriovenous fistula is the best choice for hemodialysis. It provides ideal blood flow and has the lowest chance of infection. The fistula should be placed at least 2 to 3 months before the patients start dialysis to allow time for it to mature (Brunner \& Suddarth, 2014).

Chronic kidney disease (CKD) is a worldwide health problem, and about $11 \%$ of the population being affected (Brunner \& Suddarth, 2014). The total prevalence of patients on dialysis is 264 per million population(pmp) and prevalence rate of ESRD in Assiut governorate during the year 2014 was 366 pmp (Ahmed \& Yassin,2016). For starting the hemodialysis session the vascular access must be done. In Egypt, $35.9 \%$ of access are failed to mature for use in dialysis (Coodkin, 2010).

There are several risk factors leading to vascular access failure such as age, obesity, female gender, diabetes, myocardial infarction, coronary bypass, and stroke (Georg, 2012 \& Sarı et al., 2016).

Patients frequently need information not only about the disease and its treatment but also for how to care for vascular access site and need information about risk factors leading to vascular access failure (Georg \& Simth, 2012).

The nurse should assess the vascular access for patency and takes precautions to ensure that the extremity with the vascular access is not used for measuring blood pressure or for obtaining blood specimens. Tight dressings, restraints, or jewelry over the vascular access should be avoided. The bruit over the venous access site must be evaluated at least every 8 hours because the absence of bruit may indicate blockage or clotting in the access. The nurse observes the patient for signs and symptoms of infection, such as redness, swelling, and fever (Kathleen, 2014 \& Brunner, 2016).

\section{Significance of the study}

Vascular access failure leading to increase hospital costs and patients wait for long period to perform another one and made dialysis through temporary vascular access. According to Assiut University Hospital records the number of the patients who underwent hemodialysis about 360 patients during (2016) out of this number about 200 patients had chronic renal disease. So, this study was carried out to identify risk factors leading to vascular access failure, to develop nursing guidelines which will provide the patient with necessary instructions on how to care for vascular access and to decrease vascular access failure.

\footnotetext{
Aim of the study

Aims of the present study were to:

1-Assess patient's knowledge about vascular access.

2-Identify risk factors leading to vascular access failure.
} 
3-Develop nursing guidelines for patients with vascular access.

Research questions

This study will be conducted to answer the following questions:

1-What are the risk factors leading to vascular access failure among hemodialysis patients?

2-What is the patient's knowledge about vascular access?

\section{Patients \& Method}

Research design

A descriptive exploratory research design was utilized in this study.

\section{Setting}

This study was conducted in Dialysis Unit at Assiut University Hospital.

\section{Subjects}

The study sample consisted of all available adult patients with chronic renal failure attended to hemodialysis unit with vascular access at Assuit University Hospital within a period of 6 months from the end of May to the beginning of November 2017, both sex, their age ranged from 20 to 65 years, and agreed to participate in the study.

\section{Tools of the study}

Tool 1:Patients interview questionnaire sheet: It was developed by the researcher after reviewing national and international literature under guidance of supervisors. It included three parts:

Part 1: Demographic data of the study sample: It was developed to assess the patient's demographic characteristic such as (patient name, age, sex, level of education, marital status, residence, and occupation).

Part 2: Past and present health history:

This part was developed to identify the patients' medical diagnosis and presence of chronic disease.

Part 3: Patients knowledge about vascular access: It was developed to assess patient's knowledge about vascular access as (Definition, types, indications, contraindications, complications of vascular access, and how to care for vascular access).

Tools 2: Risk factors and causes of vascular access failure It include two parts:

Part 1: Risk factors for vascular access failure:

It was developed to assess risk factors for vascular access failure as (age, gender, diabetes, obesity, smoking...).

Included complete blood picture, kidney function test, and prothrompine time and concentration

Part 2: Laboratory investigations:

Method

Ethical considerations
An official permission to conduct this study was obtained from the ethical committee in the faculty of nursing.

- The study followed common ethical principles in clinical research.

- Patient's agreement was obtained orally.

- Patient's name was coded for data entry, so that their name couldn't be identified and data will be assured confidentially and anonymity.

- There is no risk for study subjects during application of the research.

- Confidentiality and anonymity was assured.

- Study subject privacy was considered during collection of data.

- Patient's had the right to refuse to share in the study without any causes at any time.

\section{Content validity}

It was established by panel of five expertise (3 teaching staff of Medical Surgical Nursing, Faculty of Nursing , Assiut University and 2 lecturer of medical staff) who reviewed the tools for clarity, relevance, understanding and easiness minor modification were require . Reliability of the tools was done to examine the internal consistency the proposed tools was ascertained with crombach's alpha $=0.88$

\section{Pilot study}

A pilot study was conducted on $10 \%$ of patients (20 patients) in selected setting to evaluate the clarity, feasibility, and applicability of the tools.

Statistical analysis

The statistical package for (SPSS ) version (23) was used to analyze data. Descriptive statistical was used for the quantitative data in the all questionnaire and the demographic data. Descriptive statistics included: frequencies, and percentages, mean \pm SD. Use person chi-square (cross taps test) between patient knowledge and socio demographic data were done, independent t-test and person correlation (correlation is significant at the 0.05). The level of significance for this study was set at $(\mathrm{P}<0.05)$ to detect any indication of differences found in the data available. 
Result

Part 1 : Demographic characteristics and medical history.

Table (1): Distribution of demographic characteristic among the studied patients $(n=200)$.

\begin{tabular}{|c|c|c|}
\hline Variables & $\mathbf{N}$ & $\%$ \\
\hline \multicolumn{3}{|l|}{ Age group } \\
\hline $18-28 y r s$ & 43 & 21.5 \\
\hline $29-38$ & 50 & 25.0 \\
\hline $39-48 y r s$ & 52 & 26.0 \\
\hline 49 and more & 55 & 27.5 \\
\hline Mean age & \multicolumn{2}{|c|}{$40.76 \pm 13.24$} \\
\hline \multicolumn{3}{|l|}{ Sex } \\
\hline Male & 100 & 50.0 \\
\hline Female & 100 & 50.0 \\
\hline \multicolumn{3}{|l|}{ Marital status } \\
\hline Single & 45 & 22.5 \\
\hline Married & 124 & 62.0 \\
\hline Divorce & 20 & 10.0 \\
\hline Widow & 11 & 5.5 \\
\hline \multicolumn{3}{|l|}{ Level of education } \\
\hline Educated & 144 & 72.0 \\
\hline Uneducated & 56 & 28.0 \\
\hline \multicolumn{3}{|l|}{ Occupation } \\
\hline Work & 98 & 49.0 \\
\hline Not work & 102 & 51.0 \\
\hline \multicolumn{3}{|l|}{ Residence } \\
\hline Urban & 100 & 50.0 \\
\hline Rural & 100 & 50.0 \\
\hline
\end{tabular}

\section{fig.3:Prevelance of vascular access failure among patient} participant $\mathbf{n}=\mathbf{2 0 0}$

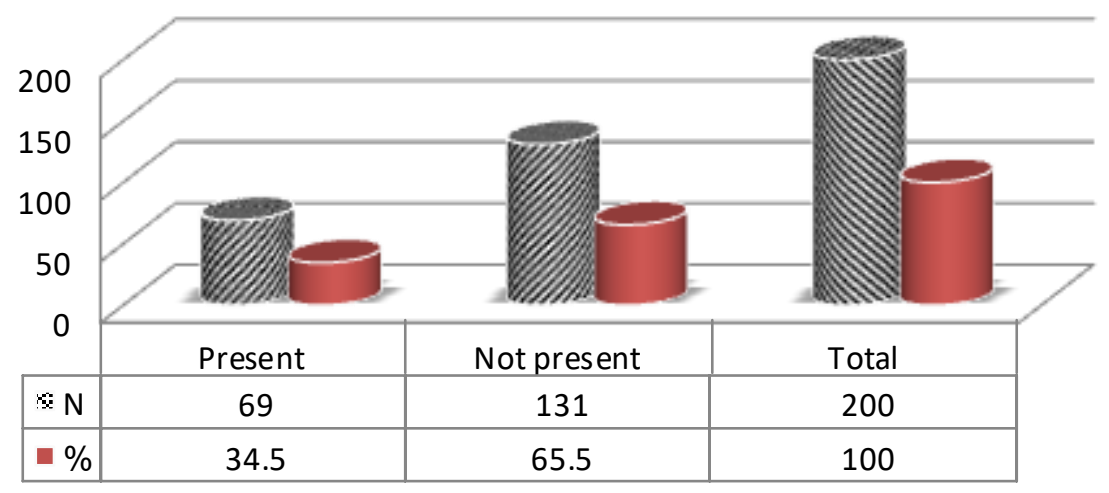

Part3 : Prevalence and risk factors of vascular access failure. 


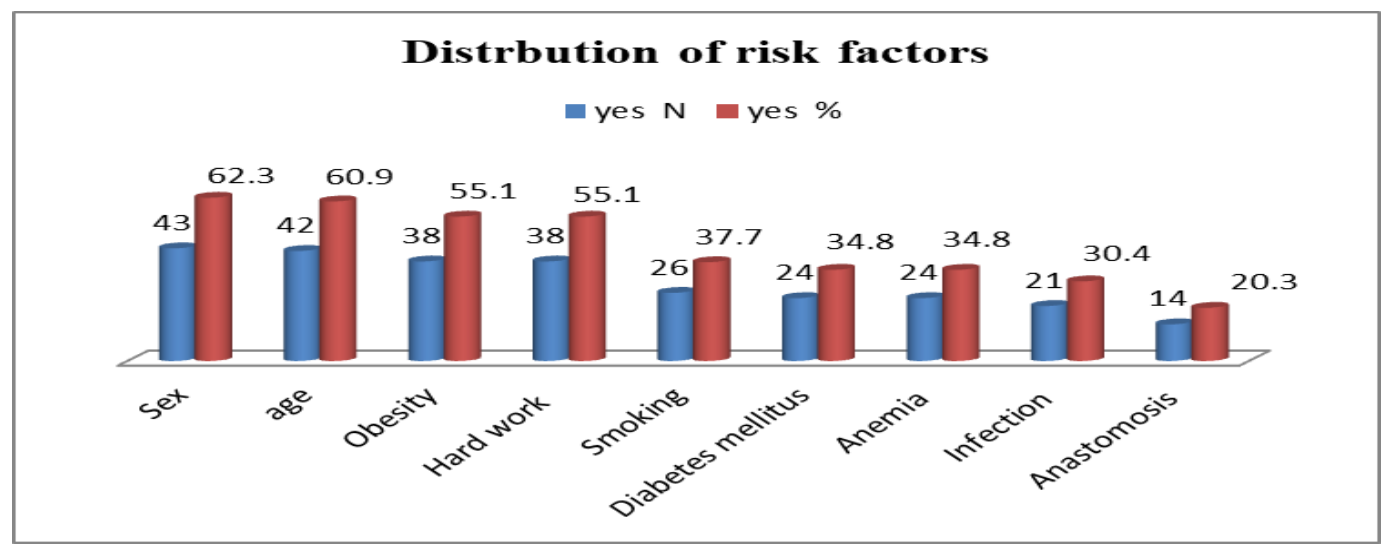

Figure 2: Risk factors for vascular access failure $(n=69)$

Table (1): Shows that the mean age of the studied sample was $(40.76 \pm 13.24)$, the highest percentage of them was married (62\%), educated $(72 \%)$, and not work $(51 \%)$. Half of them $(50 \%)$ were male and from urban.

Figure (1): Show the prevalence of vascular access failure among studied patients.

Figure (2): Show the Risk factors for vascular access failure $(n=69)$.

\section{Discussion}

Demographic characteristics regarding the demographical characteristics, the present study showed that about half of the patients were female and the other half were male and the mean age of patients was 40.47 years. This result confirmed by Tarek (2016) who carried out a systematic review and meta-analysis on 300 patients which revealed that the number of the male and female under hemodialysis with vascular access were equal and their mean age was 46.78 .

When looking at occupation and residence in relation to vascular access failure, we found that there was no significant statistical difference between patients who developed vascular access failure and those patients who not developed vascular access failure regarding occupation and residence. This result disagree with Windus (2009) who found that urban, residence and working patients were significantly linked with access failure.

Regarding to level of education in relation to vascular access failure, the present study found that there was a significant statistical difference between patients who developed vascular access failure and uneducated patients. This result agreed with Relly (2011) who found that risk of access failure increase among uneducated patients.

\section{Prevalence of vascular access failure:}

The result of this study explored that incidence of vascular access failure among hemodialysis patients at Assiut University Hospital over six months period was about one third of the total cases. This result was similar to that reported by Feldman et al. (2006) who found that primary failure rate was one third of the patients.

Risk factors for vascular access failure

This study show that, there was a high a significant statistical difference between the patients with vascular access failure and those patients who have not failure regarding to age. This study supported by Huijbregts (2010) who found that increase age was a risk factor for access failure.

The current study show that, there was no significant statistical difference between the sex and presence of vascular access failure. This study disagree with Feldman (2006) who found that female are greater risk for access failure than the male.

Regarding body mass index and hard work this study show that increase body mass index and hard work can lead to vascular access failure. This result was in the same line with Collins (2010) who found that increase body weight and extreme work are leading to vascular failure.

This current study reveled that tobacco smoking is a risk factors for vascular access failure. This agree with Georg \& Simth, (2017) who told that smoking is a risk factor for vascular disease and this lead to access failure.

The current study show that there was a significant statistical relation ship between vascular access failure and diabetes mellitus. This result agree with Ghonemy et al., (2016) Who reported that diabetes mellitus was the second most common risk factors leading to vascular failure. Also Ratnaja \& Susan (2007) reported that infection of the vascular access was increased in patients with DM hand and this lead to vascular access failure.

The present study show that anemia is one of the risk factor leading to access failure because anemic patients high risk for infection. This agree with 
Gheith \& Kamal (2008) Who reported that severe anemia was linked with access failure.

The present study show that the infection at access site was a risk factor for access failure and presence of the infection at the access site. This study confirmed by Relly (2011) who found that the infection of the vascular access was the second common causes of vascular access failure.

The present study shows that race not linked with access failure. This result not agree with Astor (2002) who reported that black patients on HD have been found to be at increased risk for vascular access complications and failure compered with not black patients.

\section{Conclusion}

The incidence of vascular access failure among hemodialysis patients at Assiut University Hospital over six months was (34.5\%). Sex and age were the most common risk factors for vascular access failure $(62.3 \%$ and $60.9 \%)$ respectively followed by hard work $(55.1 \%)$, smoking $(37.7 \%), \mathrm{DM}$ and anemia were about $(34.8 \%)$, and infection $(30.4 \%)$, while hypotension was the lowest one $(4.3 \%)$. There was statistical significant relation ship between the vascular access failure and $\mathrm{RBC}$ and $\mathrm{Hgb}$, and there were a significant statistical differences between vascular access failure and kidney function tests.

\section{Recommendations}

-Simple illustrated guidelines about vascular access and risk factors for vascular access failure should be available for patients in all dialysis units included . - Patient education should be an vital part of nurses duty in all hospital.

\section{References}

1. Ahmed \& Yassin (2016): Complication of Arteriovenous Fistula: A systematic Review , Clinical Journal of Nephrology, Vol (6), No(6), P155

2. Astor B., Eustace J., Klag M., Powe N., Longenecker J., Fink N., Marcovina S., Coresh J., (2002): CHOICE Study: Race-specific association of lipoprotein(a) with vascular access interventions in hemodialysis patients: The CHOICE Study. Kidney Int, Vol (61), P11151123

3. Brunner L., \& Suddarth D., (2014): Text book of medical surgical nursing. $13^{\text {th }}$ ed. Lippncott comp., Unit 2, New Yourk,Pp1540

4. Brunner L., \& Suddarth D., (2016): Text book of medical surgical nursing. $8^{\text {th }}$ ed. Lippncott company, Chapter 12, New Yourk,P1548

5. Collins S., (2010): Design of the Dialysis Access Consortium (DAC) Aggrenox Prevention Of
Access Stenosis, Journal of Biomedicine and Biotechnology, Vol (10), No(4),Pp69

6. Coodkin F., (2010): Prevalence rate of vascular access mortality, Alexandra journal of medicine, Vol (12), No(10), P207

7. Feldman H., Held P., Hutchinson T., \& Stoiber E., (2006): Hemodialysis vascular access morbidity in the United States International society Journal, Vol (22), No(11), P1091-1096

8. Georg E., \& Simth F., (2012): Factors affecting the patency of vascular access failure for dialysis access, Vol (55), No(3), Journal of vascular surgery, P849

9. Gheith O., \& Kamal M., (2008): Risk Factors of Vascular Access Failure in Patients on Hemodialysis, Iranian Journal of Kidney Diseases | Vol (2) No (4), P201-207.

10. Ghonemy T., Farag S., Soliman S., Amin E., \& Zidan A., (2016): Vascular access complications and risk factors in hemodialysis patients: A single center study, Alexandria Journal of Medicine, Vol (52), P67-71

11. Huijbregts H., \& Bots M., (2010): Hemodialysis Arteriovenous Fistula Patency Revisited: Results of a Prospective, Multicenter Initiative, Journal of the American Society of Nephrology, Vol (9), No (4), P68

12. Kathleen M., (2014): Critical care nursing, $7^{\text {th }}$ ed Lippincott company, Chapter 11 p722-725

13. Lewis, Shannon R., \& Margaret M., (2014): Medical surgical nursing, chapter 47,2 th $\mathrm{ed}$, Lippincott company, P1162

14. Ratnaja K., Susan H., (2007): Central venous catheter-related bacteremia in chronic hemodialysis patients: epidemiology and evidence-based management, Nat Rev Nephrol, Vol(3), P 256-66.

15. Relly E., (2011): United States Renal Data System ,American journal of kidney diseases, vol (45), No(5), P 55

16. Sarı F., Taşkapan H., Sığırcı A., \& Akpınar B., (2016): Evaluation of Risk Factors for Arteriovenous Fistula Failure in Patients Undergoing Hemodialysis(2016), Erciyes Med J 2016, Vol(38), No(1), P12-19.

17. Tarek A., (2016): Vascular access complication and risk factors in hemodialysis patients, Alexandria journal of medicine, Vol (52), No(1), P67-71

18. Windus T., (2009): Risk factors affecting on vascular access, Clinical Journal of the American Society of Nephrology, Vol(5), No (10), P43. 